\title{
High altitude exposure reduces bronchial responsiveness to hypo-osmolar aerosol in lowland asthmatics
}

\author{
L. Allegra*, A. Cogo**, D. Legnani*, P.L. Diano*, V. Fasano*, G.G. Negretto**
}

\begin{abstract}
High altitude exposure reduces bronchial responsiveness to hypo-osmolar aerosol in lowland asthmatics. L. Allegra, A. Cogo, D. Legnani, P.L .Diano, V. Fasano, G.G. Negretto. (C)ERS Journals Ltd. 1995.

ABSTRACT: It is well-known that many patients with asthma undergo clinical improvement during a stay at high altitude. At high altitude, the atmospheric and climatic conditions (such as hypoxia, cold and dry air inhalation) could modify the bronchial responsiveness in asthmatics. Our study was designed to assess the difference in bronchial responsiveness to hypotonic aerosol between sea level and high altitudes in nonresident asthmatic subjects.

The results were obtained during two mountaineering expeditions above $4,000 \mathrm{~m}$ i.e. at 4,559 $\mathrm{m}$ on Mt Rosa, Italy; and at $5,050 \mathrm{~m}$ near the Mt Everest base camp in Nepal. Eleven mild asthmatics performed standard bronchial challenges with ultrasonically nebulized distilled water $\left(5 \mathrm{~min}\right.$ inhalation, delivery $\left.2 \mathrm{~mL} \cdot \mathrm{min}^{-1}\right)$ at sea level and after staying at least $72 \mathrm{~h}$ at the above mentioned altitudes. The decrease in forced expiratory volume in one second (FEV1) from baseline was used as index of bronchial response.

There was no significant difference in pre-challenge FEV1 between sea level and high altitude in either study. However, the bronchoconstriction response to ultrasonically nebulized distilled water was significantly reduced at high altitude in both studies. At sea level the mean FEV1 decrease was $22.2 \%$ (range 15-35\%), whereas at the maximal altitude it was $6.7 \%$ (range $2-11 \%$ ).

Our results indicate that there is a reduction in bronchial responsiveness to hypoosmolar aerosol at high altitude. This suggests that atmospheric and climatic conditions, or physiological adaptations, via mediators such as atrial natriuretic peptide, are beneficial to patients with asthma at high altitude.

Eur Respir J., 1995, 8, 1842-1846.
\end{abstract}

*Institute of Respiratory Diseases University of Milan, Italy, **Institute of Infectious and Respiratory Diseases, University of Ferrara, Italy.

Correspondence: L. Allegra Litta I.R.C.C.S. Policlinico via Francesco Sforza 35

Milan

Italy

Keywords: Asthma

bronchial responsiveness

high altitude

Hypoxia

Received: December 241994

Accepted after revision July 11995
At high altitude (HA) barometric pressure, inspiratory $\mathrm{O}_{2}$ pressure, air density, relative humidity and temperature progressively decrease[1-4]. When people normally living at sea level (SL) reach HA, some compensatory responses take place: minute ventilation, heart rate and cardiac output suddenly increase, and some hormonal changes occur [2-7].

The above mentioned atmospheric and climatic conditions can modify the respiratory function and bronchial responsiveness of asthmatic subjects. Acute mild hypoxia increases bronchial responsiveness both in humans and animals [8-10], although for subjects submitted to acute, severe hypoxia, this effect is absent [11]. Breathing cold air increases bronchial reactivity to histamine in normal and asthmatic subjects [12, 13]. Furthermore, a physical effort is required to reach HA and the exercise-induced bronchospasm is known to be influenced by changes in water content and temperature of the inspired air: bronchoconstriction following exercise is maximal if the exercise is performed breathing dry cold air, and is related to the degree of hyperventilation [14, 15]. Therefore, at $\mathrm{HA}$, increasing hypoxia and hyperventilation of cold and dry air could be expected to induce bronchospasm in hyperresponsive subjects. Although some data are available about nonspecific bronchial challenge during acute simulated altitude $[8,9,11]$, much less is known about bronchial responsiveness in nonresident asthmatics during a stay at HA [16]. Our study was designed to determine the effect of progressive, prolonged exposure to an HA environment on nonspecific bronchial responsiveness to an osmotic challenge in lowland asthmatic subjects. A change in osmolarity of the airways is a potent stimulus for provoking an attack of asthma; we therefore speculated that a test changing the osmolarity of the fluid in the airways could have been appropriate for the assessment of bronchial responsiveness in HA environment.

The data were collected during two different HA mountaineering expeditions with a stay exceeding $72 \mathrm{~h}$ at the highest altitudes reached. 


\section{Material and methods}

\section{Study subjects}

Eleven fit adult subjects ( 1 female and 10 males, 23-48 yrs of age, mean \pm sD age $36 \pm 11$ yrs) affected by mild allergic asthma, according to the definition of the National Heart, Lung and Blood Institute (NHLBI) [17], were enrolled in the two studies. Study A: three asthmatic subjects (males; aged 30, 30 and 46 yrs; mean \pm sD $35 \pm 8$ yrs). Study B: eight asthmatic subjects (1 female (subject, No. 8 of table 1), and 7 males; age $38 \pm 9$ yrs).

Subjects were selected among out-patients attending our clinic, who were responsive to ultrasonically nebulized distilled water (UNDW). Atopy was examined both by skin-prick test and by measurement of specific immunoglobin E (IgE) in serum.

All subjects were asymptomatic at the time of the studies. None of them received inhaled or systemic steroids, cromolyn sodium or nedocromil, nor had they been affected with respiratory tract infections for at least the previous
6 weeks. No oral bronchodilators were used by any subject; inhaled bronchodilators were withdrawn at least 12 $\mathrm{h}$ before the tests.

At high altitude, none of the subjects were taking drugs often used as prophylaxis for mountain sickness (i.e. acetazolamide).

An informed consent and approval by the Ethics Committee were obtained prior to departure.

\section{Study design}

Bronchial responsiveness to UNDW [18-20] was assessed at SL and HA. In both studies, the subjects performed the same tests at SL and at the highest altitude reached, after a 3 days stay. During Study B, bronchial reactivity was assessed again after a further 2 days. The high altitude laboratories were reached after slow trekking, because of the long distances and to avoid the risks of rapid ascent.

Study A: tests were carried out at SL and at the Regina Margherita Hut (4,559 m, Mt Rosa, Italy), reached after 3 days trekking. Study B: tests were carried out at SL

Table 1. - Demographic and spirometric characteristics of the subjects and individual pre and postchallenge (with UNDW) levels of FEV 1 both at sea level (SL) and high altitude (HA)

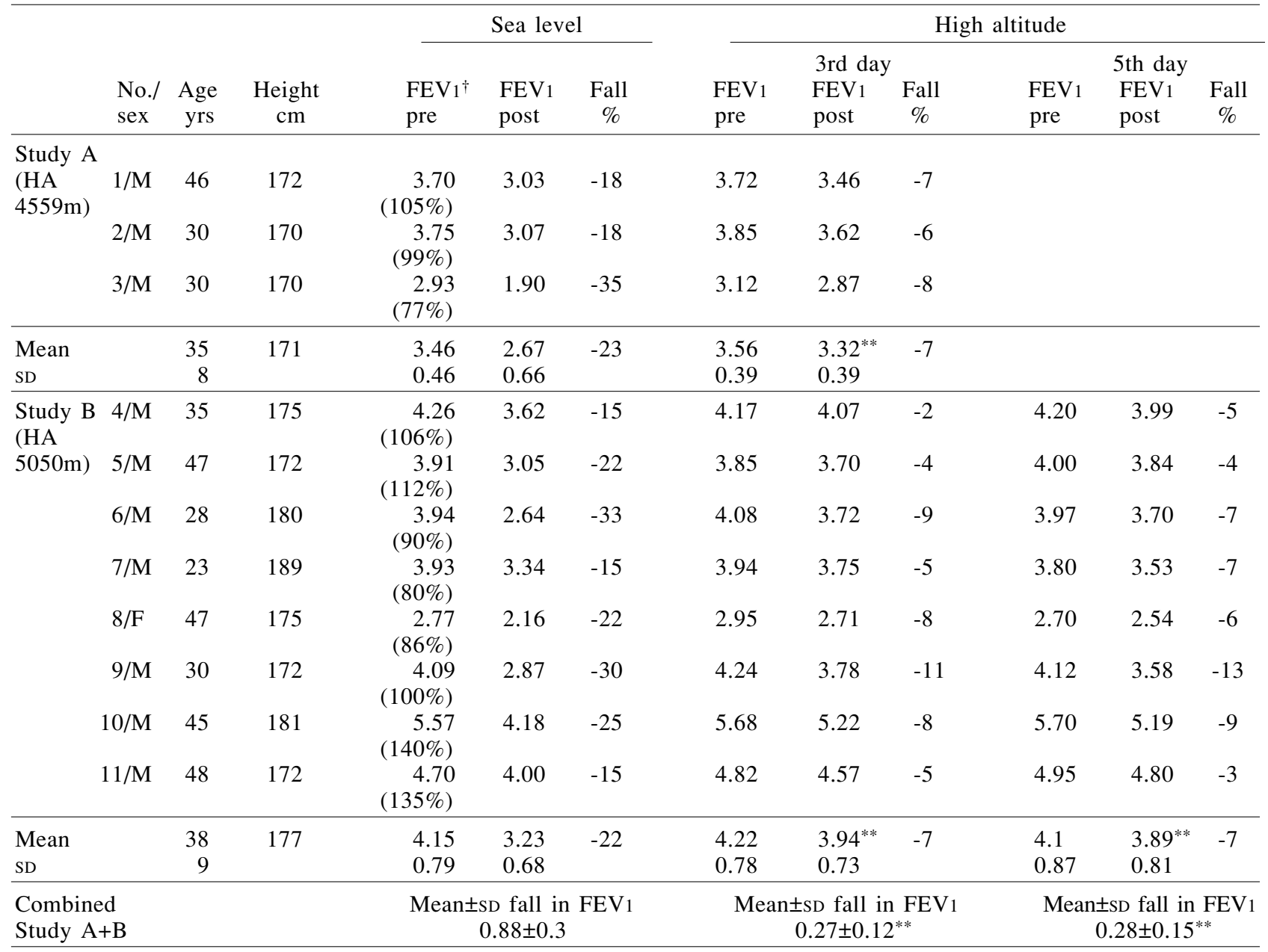

$\dagger:$ numbers in brackets are \% predicted. No significant difference was found between baseline values at SL and HA; the postchallenge fall in FEV1 was significantly less at HA than at SL ${ }^{* *}$ : $\left.\mathrm{p}<0.001\right)$. UNDW: ultrasonic nebulized distilled water. FEV1: forced expiratory volume in one second; M: male; F: female. Study A on Mount Rosa, Study B on Mount Everest. 
and at the Italian National Research Council Pyramid Laboratory (5,050 $\mathrm{m}$ near the Mt Everest base camp, Nepal) reached after 6 days trekking.

At these altitudes, barometric pressures were $57.7 \mathrm{kPa}$ $(433 \mathrm{mmHg})$ and $54 \mathrm{kPa}(405 \mathrm{mmHg})$ and inspiratory oxygen tension $\left(\mathrm{P} \mathrm{I}, \mathrm{O}_{2}\right)$ approximately $11.6 \mathrm{kPa}(87 \mathrm{mmHg})$ and $10 \mathrm{kPa}(75 \mathrm{mmHg})$ in Study A and $\mathrm{B}$, respectively (corresponding to a simulated hypoxia with an inspiratory oxygen fraction $\left(F \mathrm{I}, \mathrm{O}_{2}\right)$ of 12 and $10.5 \%$, respectively). Indoor relative humidity ranged $55-70 \%$ at SL and $28-35 \%$ at HA. At the time of the tests, the room temperature was $20^{\circ} \mathrm{C}$ at SL and ranged $14-18^{\circ} \mathrm{C}$ at $\mathrm{HA}$.

Testing of lung function and of airways response to UNDW was always performed between 11 a.m. and 1 p.m. At HA subjects were not allowed to leave the laboratory or to take exercise in the morning before tests.

First aid medical equipment (drugs, $\mathrm{O}_{2}$ canister, portable hyperbaric bag) and a rescue helicopter were available both in the high altitude laboratories and during trekking.

\section{Spirometry}

Flow-volume curves were performed using an automated spirometer (Printer-MicroMedical, Manchester, UK), tested at each altitude by a $4 \mathrm{~L}$ pump. The best of two values of forced expiratory volume in one second (FEV1) was chosen for the statistical analysis.

\section{Bronchial responsiveness}

Bronchial responsiveness to UNDW for $5 \mathrm{~min}$ [18] was assessed by means of an ultrasonic nebulizer $\left(\mathrm{MistO}_{2}\right.$ gen, Timeter, Oregan Pile, PA, USA); the respiratory tests were performed immediately before and 2 min after the challenge. The FEV1 decrease was used as index of bronchial response. The best of two FEV1 was chosen for the statistical analysis.

Nebulizer output was measured both at SL and HA in order to be sure of a steady delivery of water. The output of the nebulizer per minute was measured by weighing the canister plus the tube before and after the test, and dividing the total dose delivered over the total time of exposure: at SL the cumulative water loss was $8 \%$ less than at HA, but the difference was not statistically significant $(\mathrm{p}=0.07)$.

\section{Analysis}

The paired t-test was used to compare baseline spirometry and FEV1 decrease induced by UNDW at SL and HA: Analysis of variance (ANOVA) was used to compare the response to the challenge at SL and HA. The absolute FEV1 decrease was used to compare the response to UNDW at SL and HA of all subjects (Study A+B).

All reported differences are considered significant at a p-value of less than 0.05 .

\section{Results}

None of the subjects complained of symptoms of acute mountain sickness or asthmatic attacks during the trekking and the HA stay. No rescue medication was ever needed. The individual characteristics, the pre- and post-challenge FEV1 at SL and HA and the fall in FEV1 are reported in table 1 .

Study A: at SL the mean FEV1 (SD) decreased by $23 \%$ after the challenge from $3.46(0.46) \mathrm{L}$ (93\% of predicted value) to $2.67(0.66) \mathrm{L}$; at $4,559 \mathrm{~m}$ the mean FEV1 decreased by $7 \%$ after the challenge from $3.56(0.39) \mathrm{L}$ (96\% pred) to $3.31(0.39) \mathrm{L}$.

Study B: at SL the mean FEV1 decreased by $22 \%$ after the challenge from $4.14(0.79) \mathrm{L}(105 \%$ pred) to $3.23(0.69) \mathrm{L}$; at $5,050 \mathrm{~m}$ the mean FEV1 decreased by $6 \%$ from $4.21(0.79) \mathrm{L}(107 \%$ pred) to $3.94(0.73) \mathrm{L}$ at the third day, and from 4.18 to $3.89 \mathrm{~L}$ at the fifth day.

Study A+B: the mean FEV1 decrease was $0.88(0.3) \mathrm{L}$ at SL and $0.27(0.12) \mathrm{L}$ at HA, respectively $-22.2 \%$ and $-6.7 \%$. Basal FEV1 at SL and HA were not different ( $\mathrm{p}=0.07$ and 0.09 for Study A and B, respectively); whereas, the decrease of FEV1 induced by the challenge was always significantly higher at SL than at HA $(\mathrm{p}<0.001$; $\mathrm{t}=9.3$ ).

There was no significant difference in prechallenge levels of FEV1 measured at SL and at HA either in Study A or study B.

\section{Discussion}

Asthma is known to undergo clinical improvement at altitudes up to $1,500-2,000 \mathrm{~m}[21,22]$, probably on account of the reduction or absence of pollutant exposure, pollen and mite concentration [23-28]. Although asthma death rates have not been reported to decrease at altitude, a stay at moderate altitude often benefits asthmatic subjects [25]. Moving asthmatic atopic children with major sensitivity to house mite to a moderate altitude is associated with a reduction of bronchial hyperresponsiveness [27, 28]. Up to now, very little was known about the behaviour of asthmatic subjects at higher altitudes, where hypoxia and the other characteristics of a mountainous climate become more evident, and can worsen asthma and bronchial responsiveness [16]. In fact, cold dry air and exercise are known to induce bronchoconstriction and increase bronchial responsiveness.

Our results show that, in a group of mildly asthmatic subjects, progressive and prolonged exposure to a HA environment reduced the bronchial response to an osmotic challenge. Furthermore, these patients did not have any asthmatic attacks during trekking, when hyperventilation was maximal due to the physical effort. Their baseline respiratory function (FEV1) did not significantly differ at HA compared to SL. Actually, at HA the reduced density of the air is known to improve expiratory flow and to decrease airway resistance: the value of FEV1, however, does not significantly vary with respect to the altitude where the test is performed [29, 30].

These results could be explained by a number of factors related to inhalation challenge, environmental characteristics, or subjective compensatory responses. During challenge, the amount of water delivered was slightly (but not significantly) higher at HA than at SL, probably due to the level of ventilation (which is known 
to be higher at HA than at SL). The nebulizer output is known to increase linearly with increasing ventilation [31].

In accordance with our protocol, we exposed the subjects only to a single dose (5 min inhalation [18]), and did not make a dose-response curve. Therefore, we could only observe a significant reduction of responsiveness to the same amount of water delivered, without determining the provocative dose that would also cause the same fall in FEV1 at HA.

Concerning environmental factors, HA climate is characterized by increasing hypoxia, cold, and decreasing relative humidity. The exposure to mild or severe acute simulated hypoxia may affect bronchial responsiveness in different ways: acute exposure to a simulated altitude of 2,800 m significantly enhanced bronchial responsiveness to aerosolized methacholine in asthmatics [8]; whereas, severe, acute hypoxia (simulated altitude ranging between 5,800 and 8,300 $\mathrm{m}$ ) had no effect on bronchial responsiveness to hyperventilation with dry air in a similar group of subjects [11]. No increase in plasma catecholamines or heart rate occurred during the first study [8]; whilst a significant increase in heart rate, reflecting increased sympatho-adrenal activity, was measured in the second study [11]. The authors speculate that mild, acute hypoxia has a bronchoconstrictor effect, whilst a more severe hypoxia increases adrenal secretion, so counteracting the bronchoconstrictor effect induced by a lesser degree of hypoxia.

Unlike our study, in the simulated high altitude studies reported above, exposure to hypoxia was sudden, and the subjects breathed room air immediately followed by the hypoxic mixture, thus simulating a very rapid ascent. In these studies, the other conditions of HA environment were not reproduced, so that the degree of hypoxia was the only variable.

The environmental and physiological conditions in our studies were quite different. The level of hypoxic stimulus was graded (4-6 days spent reaching the high altitude laboratories), and the other features of HA environment (cold, wind, dry air) became progressively more evident.

Concerning the inhalation of cold air, this is known to enhance bronchial responsiveness, whereas exposure to severe cold induces refractoriness [32]. At HA, our subjects were not allowed to leave the laboratories and to exercise in the morning before the challenges, having spent the preceding night in well-conditioned rooms, so that we could exclude the presence of a refractory period or of a cold-induced inhibition when the osmotic challenge was carried out [33].

Finally, some considerations on the possible role of compensatory responses. When a lowlander spends a period of time at an altitude above $3,000 \mathrm{~m}$, a series of compensatory responses takes place (acclimatization process). Among these physiological changes, elevated plasma levels of norepinephrine, epinephrine and cortisol have been noted. In fact, cortisol secretion rises during the first 2 weeks at altitudes up to $5,000 \mathrm{~m}$, later returning to values similar to those at SL.

Catecholamine secretion only increases during the first days of exposure to moderate altitudes $[2,4,34,35]$.
Therefore, in accordance with these reports, plasma cortisol and catecholamine concentrations were probably also increased in our subjects, thus contributing to the reduction of bronchial responsiveness at HA.

An increase of atrial natriuretic peptide (ANP) has recently been reported at high altitudes, especially in subjects with acute mountain sickness [36]. In healthy subjects (i.e. without symptoms of acute mountain sickness) ANP is only slightly increased and a significant difference compared to lowland levels is present only on the first day; nevertheless, we cannot exclude a higher secretion of this peptide in our subjects in response to hypoxia. This fact is interesting, because recent data support a role for ANP in the regulation of bronchial tone, and augmented plasma ANP concentration can reduce bronchial reactivity in asthmatic subjects [37, 38]. It is, therefore, possible that, under hypoxic conditions, increased ANP levels - however slight - could have contributed to a reduction in bronchial responsiveness.

However, we cannot exclude that the other, altituderelated characteristics of mountain environments may have modulated bronchial responsiveness to osmotic challenge.

At HA, higher evaporative water loss from the airways (in order to humidify the dry air inhaled), cold, hypoxiainduced hyperventilation, and exercise could all per se change the osmolarity of the fluid in more proximal airways, thus reducing the effectiveness of an osmotic challenge. However, to our knowledge, no attempts to repeat osmotic challenges at progressively decreasing humidity and temperature conditions have ever been made, so that we cannot exclude a progressive adaptation of airways to gradual changes in the temperature and humidity of inhaled air, resulting in partial refractoriness and in reduction of bronchial hyperresponsiveness. At HA, the bronchial responsiveness to a stimulus acting directly on smooth muscle, such as methacholine and histamine, could therefore be different.

In our research, in addition to the lesser degree of induced bronchial obstruction, we did not observe any asthmatic attacks either during the stay at high altitude or during the high physical effort of trekking.

In conclusion, many factors may explain our observations: the reduction or absence of pollutants, pollen or house dust mite, which could per se decrease bronchial responsiveness; a speculated, progressive adaptation of the airways to changes in fluid osmolarity, or a more prolonged refractoriness than at SL; a protective role of higher levels of suprarenal hormones and/or ANP, which can only be speculative in our subjects, in accordance with several reports by other researchers.

\section{References}

1. International Civil Aviation Organization. Manual of ICAO Standard Atmosphere. 2nd Ed. Montreal, Quebec, 1964.

2. West JB, Lahiri S, (eds). High altitude and man. Bethesda, MD, American Physiological Society, 1986.

3. West JB. High altitude. In: Crystal RG, West JB, (eds). The Lung. New York, Raven Press, 1991; pp. 2093-2107.

4. Heath D, Williams DR. Man at high altitude. Edinburgh, Churchill Livingstone, 1981. 
5. Easton PA, Slykermann LJ, Anthonisen NR. Ventilatory response to sustained hypoxia in normals adults. $J$ Appl Physiol 1986; 61: 906-911.

6. Beder P, Weil J, Reeves J, Moore L. Breathing pattern in hypoxic exposures of varying duration. J Appl Physiol 1987; 62: 640-645.

7. Koller EA, Bischoff M, Buhrer A, Felder R, Schopen M. Respiratory, circulatory and neuropsychological responses to acute hypoxia in acclimatized and nonacclmatized subjects. Eur J Appl Physiol 1991; 62: 67-72.

8. Denjean A, Roux C, Hervé P, et al. Mild isocapnic hypoxia enhances the bronchial response to methacholine in asthmatic subjects. Am Rev Respir Dis 1988; 138: 789-793.

9. Ahmed T, Marchette B. Hypoxia enhances nonspecific bronchial reactivity. Am Rev Respir Dis 1985; 132: 839-844.

10. Denjean A, Canet E, Praud $J P$, Gaultier C, Bureau M. Hypoxia induced bronchial responsiveness in awake sheep: role of carotid chemoreceptors. Respir Physiol 1991; 83: 201-210.

11. Tam EK, Geffroy A, Myers DJ, Seltzer J, Sheppard D, Boushey HA. Effect of eucapnic hypoxia on bronchomotor tone and on the bronchomotor response to dry air in asthmatic subjects. Am Rev Respir Dis 1985; 132: 690-693.

12. Amirav I, Plit M. Temperature and humidity modify airway response to inhaled histamine in normal subjects. Am Rev Respir Dis 1989; 140: 1416-1420.

13. Dosman JA, Hodgson WC, Cockcroft DW. Effect of cold air on the bronchial response to inhaled histamine in patients with asthma. Am Rev Respir Dis 1991; 144: 45-50.

14. Noviski N, Bar-Yishay E, Gur I, Godfrey S. Exercise intensity determines and climatic conditions modify the severity of exercise-induced asthma. Am Rev Respir Dis 1987; 136: 592-594.

15. Boulet LP, Turcotte H. Influence of water content of inspired air during and after exercise on induced bronchoconstriction. Eur Respir J 1991; 4: 979-984.

16. Allegra L, Bianco S, Cogo A. Broncoprovocazione aspecifica in due asmatici non nativi durante una spedizione scientifico-alpinistica. Giorn It Mal Tor 1983; 38: 513-516.

17. Sheffer A. International Consensus Report on Diagnosis and Management of Asthma. National Heart, Lung and Blood Institute, Bethesda, Maryland, 1992.

18. Allegra L, Bianco S. Nonspecific bronchoreactivity obtained with an ultrasonic aerosol of distilled water. Eur J Respir Dis 1980; 6 (Suppl. 106): 41-49.

19. Schoeffel RE, Anderson SD, Altounyan REC. Bronchial hyperreactivity in response to inhalation of ultrasonically nebulized distilled water and saline. $\mathrm{Br}$ Med $\mathrm{J}$ 1981; 283: 1285-1287.

20. Anderson SD, Schoeffel RE. The inhalation of ultrasonically nebulized aerosol as a provocation test for asthma. In: Hargreave FE, Woolcock A eds. Airway Responsiveness, Measurement and Interpretation. Mississauga, Ontario, Astra Pharmaceutical, 1985; pp. 39-48.
21. Karrer W, Schmid T, Wuttrich O, Baldi W, Gall E, Portmann HR. Respiration of patients with chronic lung disease at 500 and $1,500 \mathrm{~m}$ above sea level. Schweiz Med Wschr 1990; 120: 1584-1589.

22. Morrison Smith J. The use of high altitude treatment for childhood asthma. Practitioner 1981; 225: 1663-1666.

23. Charpin D, Birnbaum J, Haddi H, et al. Altitude and Allergy to House-Dust Mite. Am Rev Respir Dis 1991; 143: 983-986.

24. Spieksma FTM, Zuidema P, Leupen HJ. High altitude and house dust mites. Br Med J 1971; 1: 82.

25. Carswell F. Asthma and altitude. Clin Exp Allergy 1993; 23: 973-975.

26. Boner AL, Niero E, Antolini I, Valletta EA, Gaburro D. Pulmonary function and bronchial hyperreactivity in asthmatic children with house-dust mite allergy during prolonged stay in the Italian Alps. Ann Allergy 1985; 54 : 42-45.

27. Pieroni D, Boner A, Vallone G, Antolini I, Warner J. Effective allergen avoidance at high altitude reduces allergen-induced bronchial hyperresponsiveness. Am J Respir Crit Care Med 1994; 149: 1442-1446.

28. Boner AL, Peroni DG, Piacentini GL, Venge P. Influence of allergen avoidance at high altitude on serum markers of eosinophil activation in children with allergic asthma. Clin Exp Allergy 1993; 23: 1021-1026.

29. Vaughan MR, Weber RW, Nelson H. Comparison of PEFR and FEV1 in patients with varying degrees of airway obstruction. Chest 1989; 95: 558-562.

30. Welsh CH, Wagner PD, Reeves JT, et al. Operation Everest II: spirometric and radiographic changes in acclimatized humans at simulated altitude. Am Rev Respir Dis 1993; 147: 1239-1244.

31. Riedler J, Robertson CF. Effect of tidal volume on the output and particle size distribution of hypertonic saline from an ultrasonic nebulizer. Eur Respir J 1994; 7 : 998-1002.

32. Freed AN, Stream CE. Airway cooling: stimulus specific modulation of airway responsiveness in the canine lung periphery. Eur Respir J 1991; 4: 568-574.

33. Anderson SD, Smith CM. Osmotic challenges in the assessment of bronchial hyperresponsiveness. Am Rev Respir Dis 1991; 143: S43-S46.

34. Cunnigham WL, Becker EJ, Krenzer F. Catecholamines in plasma and urine at high altitude. J Appl Physiol 1965; 20: 607-610.

35. Sawhney RC, Malhotra AS, Singh T. Glucoregulatory hormones in man at high altitude. Eur J Appl Physiol 1991; 62: 286-291.

36. Bartsch P, Shaw S, Franciolli M, Gnadinger MP, Weidmann P. Atrial natriuretic peptide in acute mountain sickness. J Appl Physiol 1988; 65: 1929-1937.

37. Hulks G, Jardine AG, Connell JC, Thomson NC. Influence of elevated plasma levels of atrial natriuretic factor on bronchial reactivity in asthma. Am Rev Respir Dis 1991; 143: 778-782.

38. McAlpine LG, Hulks G, Thomson N. Effect of atrial natriuretic peptide given by intravenous infusion on bronchoconstriction induced by ultrasonically nebulized distilled water (Fog). Am Rev Respir Dis 1992; 146: 912-915. 